\title{
SEXUAL NURSING CARE FOR THE POSTPARTUM PERIOD AND ITS IMPACT ON SEXUAL DYSFUNCTION AND LIFE SATISFACTION AMONG EGYPTIAN WOMEN
}

\author{
Nabila E. Sabola ${ }^{1}$, Marwa A. Shahin ${ }^{2}$, Khaled A. Khader ${ }^{3}$, Hanan M. Metwally ${ }^{4}$ and Mervat M. Desoky ${ }^{5}$ \\ ${ }^{1}$ Faculty of Nursing, Community Health Nursing department, 32511 Shbeen El Koom, Menoufia University, Egypt ${ }^{2}$ Faculty \\ of Nursing, Maternal and New born Health Nursing department, 32511 Shbeen El Koom, Menoufia University, Egypt. \\ ${ }^{3}$ College of Applied Medical Sciences, Nursing Department -Taif University,21944 Taif, Saudi Arabia \\ ${ }^{4,5}$ Faculty of Nursing, Obstetrics and Gynecological Nursing department, 44511 Zagazig University, Egypt
}

Corresponding author: Khaled Khader

Email: khaledkhader@yahoo.com

\begin{abstract}
Many couples experience postpartum period of decreasing sexual satisfaction. Postpartum sexual dysfunction is a very common and relevant clinical problem, with significant adverse effects on women's health. The aim of this study was to evaluate the impact of sexual nursing care for the postpartum period on sexual dysfunction and life satisfaction among Egyptian women. A quasi-experimental design was used to study 219 women selected using a purposive sample. The study was conducted in out-patients maternity clinic at Zagazig university hospitals, Sharkia Governorate, Egypt, between the periods from February 2019 to February 2020. Data was collected using three tools. The first: Structured interview questionnaire that consist from three parts, part one: socio demographic characteristics, part two obstetric history and part three sexual history, the second: Female Sexual dysfunction index (FSDI), and the third: Satisfaction with Life Scale (SWLS). Four session about sexual education was done. The Results showed an improvement in sexuality and life satisfaction after application of sexual nursing care for the postpartum period including kegel's exercise, positioning and distractions techniques post intervention compared to pre intervention. The study concluded that sexual nursing intervention for postpartum period improve sexual functioning and create enjoyable intercourse and there was high positive correlation between sexuality and life satisfaction after implementation of the sexual nursing care intervention. The study recommended to provide counselling / training program about sexual nursing care intervention during postpartum period for nurses working in different health care settings.
\end{abstract}

Keywords: Sexual Nursing Care, Sexual Dysfunction, life satisfaction and postpartum

\section{INTRODUCTION}

Postpartum period is recognized as a vulnerable and stressful period for women of different cultural backgrounds, accompanied by significant social and individual changes for mothers who have many new concerns and problems during this period ${ }^{1}$. Postpartum sexual function is an important issue for couples, as the first sexual intercourse is an important step for couples to form a sincere relationship ${ }^{2}$. Childbirth contributes to structural and functional changes in the pelvic floor muscle, as most postpartum women who have complained during this time from sexual problems that these problems typically resolve one year after childbirth $^{3}$.Several factors can influence childbirth-related sexual dysfunction, such as parity, breast feeding, delivery mode, episiotomy, stress, fatigue and physical and psychological problems such as postpartum depression ${ }^{4}$.

Sexual instinct is one of man's greatest instincts that influence his conduct ${ }^{5}$. Sexual function, considered part of women's health, is an essential component of life and is a multidimensional phenomenon influenced by many biological and psychological factors ${ }^{6}$. Sexual dysfunction refers to a chain of psychiatric, individual, and couple's experiences that manifests itself as a dysfunction in sexual desire, sexual excitement, orgasm, and pain during intercourse ${ }^{7}$.

In Egypt, about 31.5 percent of women had dyspareunia and decreased sexual self-efficacy ${ }^{8}$. A study conducted in Mansoura City examined the effect of the sexual counseling program on pain and sexual function among women with dyspareunia revealed that about 27.3 per cent of the sample studied suffered of dyspareunia as a direct result of weak pelvic floor muscles following vaginal delivery ${ }^{9}$. Many couples report reduced sexual satisfaction in a relationship that is mostly related to their impaired sexual relationship. Several studies have shown a decrease in sexual satisfaction during the postpartum period ${ }^{10}$. Sexual problems have a major adverse effect on the different aspects of women's lives, including self-image, selfconfidence, sense of health, and satisfaction with relationships ${ }^{11}$.Several risk factors affect the development of sexual dysfunction and sexual satisfaction among women, such as mental health, sexual relations, female partner's sexual function, and personality-related factors, duration of sexual intercourse, infertility, drugs, chronic diseases, pelvic surgery, cancers, pregnancy, and postpartum period ${ }^{12}$. Sexual dysfunction leads to lower quality of life and 
dissatisfaction with others, negatively affecting the physical, psychological, social and emotional health of women ${ }^{13}$. Disregarding this issue often leads to a reduced sense of femininity, reduced self-confidence and wellbeing, and social problems, including divorce, violence, drug dependence, and numerous mental and physical illnesses ${ }^{14}$.

The WHO has always stressed that providing perinatal and postpartum care for mothers and babies and providing information and advice to women in accordance with their needs is an ideal opportunity to address sexual health and sexual function problems ${ }^{15}$.

Sexual problems can be complicated, and their care can be time intensive and require special training. Non-pharmacological treatments, such as sexual and couple therapy, pelvic floor exercises, psychotherapy, lifestyle changes, enhanced body image and the use of vaginal lubricants and moisturizers, are extremely important in the postpartum period ${ }^{16}$.

Women have a strong desire to be educated and to gain more information from their care providers on postnatal sexual issues ${ }^{17}$. Lack of sexual health advice after childbirth is one of the important factors leading to impaired sexual function during the postnatal period ${ }^{18}$. While sexual education after childbirth is significant, its content is currently usually focused on the time of the first intercourse and the choice of postpartum contraceptive methods that do not meet the needs of women during their postpartum period $^{19}$.

Health care workers can play an important role in helping couples cope with the postpartum period due to changes that occur during that period. This will improve the intimacy, sexual satisfaction and performance of mothers ${ }^{20}$. Teaching sex can lead to more satisfaction between couples and ultimately lead to greater satisfaction in life. As a result, divorces due to sexual problems and dissatisfaction will decrease ${ }^{21}$.

\section{Significant of the study}

Postpartum female sexual dysfunction (PPFSD) is a common health problem with different incidences reported worldwide. The problem varies in degree according to the cause. One of the main causes is weak and very weak pelvic floor muscles ${ }^{22}$. It is clear that postpartum women have a lot of sexual issues that specifically reduce their sexual self-efficacy. There is a lack of literature on the non-pharmacological measures for management of female sexual dysfunctions. Thus, the aim of the study is to evaluate the impact of sexual nursing care for the postpartum period on sexual dysfunction and life satisfaction among Egyptian women.

\section{Research hypothesis}

Women who exposed to sexual nursing care for the postpartum period will experience sexual enhancement and decreased sexual dysfunction post intervention compared to pre-intervention. -Women who exposed to sexual nursing care for the postpartum period will experience an improvement in life satisfaction post intervention compared to pre-intervention

\section{METHODS}

This study used the Quasi experimental design (Pre - post-test) to study a purposive sample of 219 women experiencing postpartum period. The inclusion criteria include lactating women in remote postpartum period (between 40 and 180 days after childbirth) from 18 till 40 years, women have active sexual life in the last month (defined as sexual activity with penetration within the previous 4 weeks). Also, free from chronic physical and mental illnesses. The inclusion criteria were assessed through interviewer assisted. The study was conducted in the Maternity Unit at outpatient clinics in Zagazig University Hospitals, Sharkia Government, Egypt for postpartum care and family planning services. This unit was selected based on the fact that it provides services to a large sector of the female's population with a high rate of postpartum women.

In the current study, the variable sexual nursing care intervention for postpartum period include nursing education about sex, pelvic floor exercises including kegel's exercise, distractions techniques as meditations, relaxations techniques and proper positioning.

Data were collected through using three tools as follows: tool (I): Structured interview questionnaire (Demographic characteristics of participants, Obstetric history, and sexual history ) that was developed by the researchers after reviewing related literatures, tool (II):Female Sexual dysfunction index (FSDI) which was adapted from Rosen et al. ${ }^{23}$, (2000): It is a 19item questionnaire that measures female sexual function in 6 areas of sexual function: sexual desire ( 2 items), sexual arousal (4 items), vaginal lubrication (4 items), orgasm (3 items), satisfaction ( 3 items), and sexual pain ( 3 items), the lowest score is 0 , the highest score is 95 , tool (III): Satisfaction with Life Scale (SWLS), which was adapted from Diener et al. ${ }^{24}$, (1985): the questionnaire contained 5 items, each was measured with three points Liker scale $(1-3)$ as (1) for "dissatisfied", (2) for neutral, and (3) for "satisfied, the lowest score is 5 , the highest score is 15 and tool (IV): Intervention program: a selflearning booklet which was prepared by the researchers and its contents was validated and then distributed to childbirth women to be used as a guide for self-learning to improve their knowledge and practice pertaining to sexual 
nursing care intervention for postpartum period. Test-retest reliability was applied by the researchers for testing the internal consistency of the instruments, Scores from repeated testing were compared. Study instruments revealed reliable at $\mathrm{a}=0.81$ for tool (I), at $\mathrm{a}=0.79$ for tool (II), $\mathrm{a}=0.90$ for tool (III) content validity were tested for all tools used in research. Pilot study was performed and considered. All Ethical issues were also considered: According to the Faculty of Nursing staff scientific and ethical research committee, the researcher was got the women consent before conducting the study. Assured them about confidentiality, safety and privacy data obtained.

Women were enrolled in 4 sessions about sexual education. Each session was conducted for $\mathbf{6 0 - 9 0}$ min by three obstetric researchers .one session every week. $1^{\text {st }}$ Sessions includes explanation of anatomy and physiology of female reproductive organs, stages of sexual intercourse and the normal sexual response cycle, $2^{\text {nd }}$ session: includes definition and types of female sexual dysfunction and two sessions includes sexual nursing care intervention for post partum period for managing sexual dysfunction in which women were taught how to perform Kegal exercises, relaxation, distraction techniques and positioning. After 4 weeks of conducting study intervention, the researcher assessed sexuality and life satisfaction using study tools (tool II and III).

For female sexual dysfunction assessment, the total score of each woman was categorized into "Bad level when the woman achieved $(0-<32)$ of the total score of Sexual Function Index (SFI), "Moderate level was considered when the woman achieved (32- $<65)$ of Sexual Function Index (SFI), and those who had $(65$ - 95) points were considered as "Good level of Sexual Function Index (SFI). Regarding assessing "life satisfaction", the total score of each woman was categorized into "Dissatisfied women" when the woman achieved $(5-8)$ of the total score, "Neutral women" was considered when the woman achieved (9-12), and those who had (12 - 15) points were considered as "Satisfied women".

Satisfaction with sex during pregnancy and after delivery was done by using two specific questions by researchers in the Tool $\mid$ about sexual satisfaction during pregnancy and after delivery, with a three Likert scale of 1-3, with 1 =dissatisfy, $2=$ neutral, and $3=$ satisfy.

For analysis of data collected, SPSS version 22 was used. Descriptive and inferential analysis was conducted. Qualitative data was analyzed by chisquare $\left(x^{2}\right)$ Fisher Exact test and paired $T$ test. Level of significance was set as $P$ value $<0.05$ for all significant tests.

\section{RESULTS}

A total of 219 post-partum women who agree to participate in this study, out of 253 with a response rate of $86.6 \%$. Table 1 represented sociodemographic characteristics of the studied women, it revealed that the studied women mean age was $18.6 \pm 8.4$ years and more than half of them $(53.4 \%)$ had secondary educational level. Regarding occupation, $68.0 \%$ of the studied women were housewives.

Concerning obstetric history, $61.6 \%$ of studied women delivered by cesarean section. $40.2 \%$ \& $58.0 \%$ respectively had abortion and circumcision. Regarding using of family planning methods, more than two thirds of them (64.4\%) used family planning methods; and IUD was the most family planning method used (41.1\%).

Table 2 revealed that, the majority of the studied women, before intervention, reported agreement about the 5 items of the Satisfaction with Life Scale (SWLS). However, approximately one quarter of them were disagree about these five items.

Table 3 highlights the efficacy of the sexual nursing care for the postpartum period on the studied women Female sexual dysfunction index (FSDI) domains, and its total score. Post intervention revealed a highly significant improvement $(p<0.001)$ in the different aspects of FSDI domains as well as total score, except sexual desire domain, which had also a higher post intervention mean score than pre intervention, but the difference was not significant statistically $(p=0.11)$. Post intervention (excluding sexual desire domain as composed of 2items only), sexual arousal was the highest mean domain (13.8 \pm 3.4 ) followed by vaginal lubrication domain $(13.4 \pm 2.9)$. The lowest domain was orgasm $(10.4 \pm 2)$. Pre-intervention total FSDI mean increased from $64.3 \pm 5.9$ to $68.1 \pm 7.4$ post intervention and the difference was significant statistically $(p<0.001), \quad$ which indicated improvement of women sexuality post intervention.

Table 4 showed that during pregnancy $66.7 \%$ of studied women were satisfied with sex meanwhile, after labor $42.9 \%$ of them were satisfied with sex which indicating decreased number of women who satisfied with sex after labor than during pregnancy. This difference was significant statistically $(\mathrm{p}=0.001)$. Considering mean total score of FSDI during pregnancy, it was higher (indicated higher sex satisfaction) than that of after delivery (indicated lower sex satisfaction) $(2.4 \pm 0.9 \mathrm{vr} 1.7 \pm 0.6)$, this difference was significant statistically $(\mathrm{p}=0.01)$.

Table 5 revealed the effect of sexual nursing care on sexual dysfunction and life satisfaction among studied women post intervention. It showed that 
$90.3 \%$ of studied women whom had good level of sexual function index are satisfied with sex. It also showed that level of SFI falls only in two levels which is moderate and good level of sexual function index with total absence of bad level which indicated improvement of women sexuality post intervention. Table 6 represented that studied women with good level of sexual function index score (65-95) had the higher mean score $(32.2 \pm 6.8)$ of life satisfaction post intervention compared to $23.5 \pm 7.3$ of studied women pre intervention. Finally, the study showed a significant positive Pearson correlation between total score of sexual function index and total score of life satisfaction $(P=.000)$

Table 1: Distribution of the studied women according to their Socio -demographic Characteristics, and their obstetric history. $(\mathrm{N}=219)$

\begin{tabular}{|c|c|c|}
\hline Socio -demographic characteristics & Frequency or mean \pm SD & Percent \\
\hline Age (years): mean \pm SD & $18.6 \pm$ & 8.4 years \\
\hline \multicolumn{3}{|l|}{ Education: } \\
\hline Illiterate & 60 & 27.4 \\
\hline Primary & 12 & 5.5 \\
\hline Secondary & 117 & 53.4 \\
\hline University & 30 & 13.7 \\
\hline \multicolumn{3}{|l|}{ Occupation } \\
\hline Housewife & 149 & 68.0 \\
\hline Employed & 70 & 32.0 \\
\hline \multicolumn{3}{|l|}{ Income* } \\
\hline Not enough & 154 & 70.3 \\
\hline Enough & 65 & 29.7 \\
\hline Type of delivery: CS (Yes) & 135 & 61.6 \\
\hline Abortion: Yes & 88 & 40.2 \\
\hline Mean time since last delivery (per month) & $3.9 \pm 2.1 \mathrm{~m}$ & \\
\hline $\begin{array}{l}\text { Use Family planning methods: } \\
\text { Yes }\end{array}$ & 141 & 64.4 \\
\hline If yes, what methods used? $(\mathrm{N}=141)$ & 25 & 17.7 \\
\hline $\mathrm{OC}$ & 58 & 41.1 \\
\hline IUD & 35 & 24.8 \\
\hline Injections & 10 & 7.2 \\
\hline Local & 13 & 9.2 \\
\hline Circumcision: Yes & 127 & 58 \\
\hline Total & 219 & 100 \\
\hline
\end{tabular}

*Due to Egyptian cultural rural environment and social taboo, family income data was difficult to be collected quantitatively, that is why researchers asked participants if family income was not enough or enough, depending on El-Gilany et al. ${ }^{25},(2012)$. Accordingly, income data responses are participants point of view.

Table 2: Studied women responses to individual items of Satisfaction with Life Scale (SWLS), pre intervention $(\mathrm{N}=\mathbf{2 1 9})$

\begin{tabular}{|c|c|c|c|c|}
\hline \multicolumn{2}{|r|}{ Satisfaction with Life Scale (SWLS) items } & $\begin{array}{c}\text { Disagree } \\
\%\end{array}$ & $\begin{array}{c}\text { Neutral } \\
\%\end{array}$ & $\begin{array}{c}\text { Agree } \\
\%\end{array}$ \\
\hline \multicolumn{5}{|c|}{ Satisfaction with Life Scale (SWLS) (5 items, Likert 1-3): } \\
\hline 1. & In most ways my life is close to my ideal. & 21.9 & 16 & 62.1 \\
\hline 2. & The conditions of my life are excellent. & 24.7 & 8.2 & 67.1 \\
\hline 3. & The conditions of my life are excellent. & 25.6 & 6.8 & 67.6 \\
\hline 4. & I am satisfied with my life. & 22.8 & 12.8 & 64.4 \\
\hline & $\begin{array}{l}\text { So far, I have gotten the important things I want in life. } \\
\text { mean score (SWLS) }\end{array}$ & 25.1 & 10 & 64.8 \\
\hline
\end{tabular}

NB: Total score of the SWLS scale ranged from 5-15. 
Table 3: The efficacy of the sexual nursing care on the six domains of female sexual dysfunction index scale (FSDI)and its total score pre and post intervention $(\mathrm{N}=219)$

\begin{tabular}{lccc}
\hline $\begin{array}{l}\text { Female Sexual dysfunction index (FSDI) } \\
\text { (19items, 6 domains,6 Likert scale (0 - 5) }\end{array}$ & $\begin{array}{c}\text { Pre- } \\
\text { intervention } \\
\text { Mean } \pm \text { SD }\end{array}$ & $\begin{array}{c}\text { Post- } \\
\text { intervention } \\
\text { Mean } \pm \text { SD }\end{array}$ & P value \\
\hline FSDI Domains and total score: & $5.8 \pm 1.6$ & $6.1 \pm 1.8$ & 0.11 \\
*Sexual desire (2 items) & $12.1 \pm 2.1$ & $13.8 \pm 3.4$ & $<0.001$ \\
Sexual arousal (4 items), & $11.9 \pm 3.7$ & $13.4 \pm 2.9$ & $<0.001$ \\
Vaginal Lubrication (4 items) & $9.4 \pm 1.7$ & $10.4 \pm 2$ & $<0.001$ \\
Orgasm (3 items), & $9.2 \pm 1.8$ & $12 \pm 2.6$ & $<0.001$ \\
Sexual satisfaction (3 items) & $10 \pm 2.2$ & $11.5 \pm 2.7$ & $<0.001$ \\
Sexual pain (3 items). & $64.3 \pm 5.9$ & $68.1 \pm 7.4$ & $<0.001$ \\
Total mean score(FSDI) & $50-85$ & $56-89$ & \\
Range & & & $<$
\end{tabular}

NB1: Total score of the FSDI scale ranged from 0-95.

Table 4: Distribution of the studied women according to their satisfaction with sex during pregnancy and after delivery* $(\mathbf{N}=219)$

\begin{tabular}{|c|c|c|c|c|c|c|c|c|}
\hline \multirow[b]{2}{*}{ Satisfaction with sex } & \multicolumn{2}{|c|}{ Satisfy } & \multicolumn{2}{|c|}{ Neutral } & \multicolumn{2}{|c|}{ Dissatisfy } & \multicolumn{2}{|c|}{ Mean $\quad \pm$ SD } \\
\hline & No & $\%$ & No & $\%$ & No & $\%$ & & *P value \\
\hline \multirow{2}{*}{$\begin{array}{l}\text { A. During } \\
\text { pregnancy }(\mathrm{N}=219) \\
\text { B. After delivery }(\mathrm{N}=219)\end{array}$} & 146 & 66.7 & 39 & 17.8 & 34 & 15.5 & $2.4 \pm 0.9$ & $\begin{array}{l}X^{2}=14.2, \\
P=0.001 \mathrm{HS}\end{array}$ \\
\hline & 94 & 42.9 & 114 & 52.1 & 11 & 5.0 & $\begin{array}{l}1.7 \pm 0.6 " ” \\
P=0.01\end{array}$ & \\
\hline
\end{tabular}

Table 5 : The effect of Sexual nursing care on sexual dysfunction categories and life satisfaction among studied women, post intervention

\begin{tabular}{|c|c|c|c|c|c|c|c|}
\hline \multirow{2}{*}{$\begin{array}{l}\text { Groups of total score of SFI } \\
\text { post-intervention }\end{array}$} & \multicolumn{4}{|c|}{$\begin{array}{c}\text { Groups of total score life } \\
\text { satisfaction post-intervention }\end{array}$} & \multirow{2}{*}{\multicolumn{2}{|c|}{ Total }} & \multirow{2}{*}{ P value } \\
\hline & \multicolumn{2}{|c|}{ Neutral (9-12) } & \multicolumn{2}{|c|}{$\begin{array}{c}\text { Satisfied } \\
(13-15) \\
\end{array}$} & & & \\
\hline Moderate level SFI $(32-<65)$ & 4 & 2.5 & 153 & 97.5 & 157 & 100 & \\
\hline Good level SFI score (65 - 95) & 6 & 9.7 & 56 & 90.3 & 62 & 100 & $\begin{array}{l}\text { Fisher exact } \\
\text { test }=0.03 \text { Sig. }\end{array}$ \\
\hline Total & 10 & 4.6 & 209 & 95.4 & 219 & 100 & \\
\hline
\end{tabular}

Table 6: The effect of sexual nursing care on sexual dysfunction categories and mean total score of life satisfaction among studied women

\begin{tabular}{|c|c|c|c|c|}
\hline \multirow{2}{*}{$\begin{array}{l}\text { Groups of total score of SFI pre- } \\
\text { intervention }\end{array}$} & \multicolumn{2}{|c|}{ Mean total score life satisfaction } & \multirow[b]{2}{*}{ Test of sig. } & \multirow[t]{2}{*}{ P-value } \\
\hline & $\begin{array}{c}\text { Pre } \\
\text { intervention }\end{array}$ & $\begin{array}{c}\text { Post } \\
\text { intervention }\end{array}$ & & \\
\hline Bad level SFI score $(0-<32)$ & $26.1 \pm 7.8$ & $31.1 \pm 5.4$ & $t_{- \text {paired }}=5.2$ & $\mathrm{P}=0.001$ \\
\hline Moderate level SFI (32 - <65) & $24.3 \pm 7.2$ & $30.6 \pm 16.8$ & $\mathrm{t}_{\text {-paired }}=4.3$ & $P=0.01$ \\
\hline $\begin{array}{l}\text { Good level SFI score (65 - } \\
95)\end{array}$ & $23.5 \pm 7.3$ & $32.2 \pm 6.8$ & $\mathrm{t}_{- \text {paired }}=5.9$ & $P=0.0001$ \\
\hline Total & $24.2 \pm 7.1$ & $30.6 \pm 6.6$ & $\mathrm{t}-_{\text {paired }}=6.3$ & $P=0.0001$ \\
\hline
\end{tabular}




\section{DISCUSSION}

Women experience a wide range of hormonal, physical, and emotional changes during the postpartum period, which can influence their well-being, relationship, and sexuality ${ }^{26}$. Postpartum sexual dysfunction is a very serious and important clinical problem that has a major adverse effect on the health of women ${ }^{27}$.

According to the results of the current study it can be noticed that, most of the studied women aged $18-<30$ years, more than half of them had secondary educational level and $68.0 \%$ of the studied women were housewives. This result may be due to Most of women at rural area at Egypt got married and delivered between 18-30 years and housewives due to cultural issues. These findings are in agreement with Zamani et al. ${ }^{28}$, (2019) who study the impact of postpartum sexual health therapy on women's sexual satisfaction. They reported that the mean age of participants was $29.5 \pm 4.3$. This also is congruent with Banaei et al. ${ }^{29}$, (2017) study in Iran about impact of counseling on sexual intimacy of lactating women who reported that the majority of women were housewives.

The current study showed that 64.4 per cent of studied women used methods of family planning, and IUD was the most commonly used method of family planning. These results were supported by Sok et al. ${ }^{30}$, (2016) who conducted a study of postpartum women's sexual behavior, satisfaction and contraceptive use and reported that 49 percent of women reported using contraceptive methods. The present study finding revealed that $58 \%$ of studied women had circumcision. This corroborates with the study of Elnashar et al. ${ }^{31}$, (2007) in Egypt about female sexual dysfunction in Lower Egypt who found that circumcision was a major cause of sexual problems.

The present study showed decrease number of women who were satisfied with post labor sex than during pregnancy. This result could be attributed to women face unique issues in terms of physical, psychological, social, cultural, aspects that affect their own and their spouses' quality of life and sexual health and also fatigue due to increased work pressure and baby care. This is matching with the study of Sok et al. ${ }^{30}$, (2016) who showed a decrease in postpartum sexual satisfaction. The same results were also observed by Acele and Karaçam, ${ }^{32}$ (2012) Study in Izmir, Turkey about sexual problems in women during the first postpartum year and related conditions. They concluded that $91.3 \%$ of women suffered from postpartum sexual problems.

According to the results of the current study it can be noticed that, the majority of women who had good sexual function index rates are satisfied with sex. It also showed a total absence of bad level of sexual function index which indicated improvement of women's post-intervention sexuality. This is in agreement with the study of Banaei et al. ${ }^{29}$, (2017) in Iran about impact of counseling on sexual satisfaction of lactating women. It has been shown that sexual training has been successful in that the sexual satisfaction of women and the impact of sexual training have been stable after 2 months after the training sessions have been completed. This is comparable to that reported by the study of Karimi et al. ${ }^{33}$, (2013) who mentioned that couples ' sexual satisfaction increased significantly in the intervention group rather than the control group after intervention indicating the effect of sexual health education on couples ' sexual satisfaction in the intervention group.

These results were also supported by Hosseini Zand et al. ${ }^{34}$, (2012) who conducted a study to detect the effectiveness of couple therapy based on Islamic teachings on sexual intimacy couples who referred to clinics in Tehran righteous. They mentioned that, that lack of adequate knowledge or confusion and conflicting information could contribute to couples ' vulnerability and lack of intimacy; however, when the information is provided correctly and in accordance with religion and culture, sexual awareness will be increased and more sexual intimacy will be provided.

The results of the current study demonstrated that women with a good level of sexual function index had the higher mean life satisfaction score after intervention. This might be due to higher levels of satisfaction with sex are strongly associated with higher levels of satisfaction with other important aspects of life and overall physical health, family life ${ }^{35}$. Similarly, the study of Schmiedeberg et al. (2016) ${ }^{36}$ of how sex contributes to life satisfaction concluded that individuals reported a greater increase in life satisfaction when they also experienced a more substantial increase in sexual frequency and satisfaction.

The current study showed a significant positive Pearson correlation between total score of sexual function index and total score of life satisfaction $(P=.000)$. This result is consistent with Zamani et al. ${ }^{27}$, (2019) study.

\section{CONCLUSION}

Sexual nursing care intervention for the postpartum period which includes women education about Kegal exercises, relaxation, techniques and positioning enhance sexual function and improve life satisfaction among studied women after intervention compared to before the intervention.

\section{RECOMMENDATIONS}

Holding periodic counseling/training on sexuality to enhance and strengthen sexual efficiency and 
prevent postpartum sexual problems in primary health care centers to enhance sexual intimacy and promote marital satisfaction. Training sessions to encourage women to perform postpartum pelvic floor muscle exercises that improve sexual function during postpartum visits and follow-up. Sexual intervention should be considered by health care professionals / specialists with a view of designing interventions aimed at promoting the quality of sexuality and quality of life for postpartum women.

\section{ACKNOWLEDGEMENT}

The authors would like to acknowledge deans of nursing college for their support and all nursing directors who had facilitated process of collecting data in their institutions.

\section{CONFLICTS OF INTEREST}

The authors declare no conflicts of interest.

\section{REFERENCES}

1. Ducarme G, Hamel JF, Brun S, et al. Sexual function and postpartum depression 6 months after attempted operative vaginal delivery according to fetal head station: A prospective population-based cohort study. PLoS One; 2017, 12(6): e0178915.

2. Lee JT, Tsai JL. Transtheoretical ModelBased Postpartum Sexual Health Education Program Improves Women's Sexual Behaviors and Sexual Health. J Sex Med; 2012, 9(4):986-996.

3. Chang SR, Chen KH, Ho HN, et al. Depressive symptoms, pain, and sexual dysfunction over the first year following vaginal or cesarean delivery: a prospective longitudinal study. Int J Nurs Stud; 2015, 52(9):1433-1444.

4. Banaei M, Torkzahrani S, Ozgoli G, et al. A Addressing the Sexual Function of Women During First Six Month After Delivery: Aquasi-Experimental Study. Mater Sociomed. 2018 Jun; 2018, 30(2):136-140.

5. Liu HL, Hsu P, Chen KH. Sexual activity during pregnancy in Taiwan: a qualitative study. Sex Med; 2013, 1(2):54-61.

6. Yildiz $H$. The relation between prepregnancy sexuality and sexual function during pregnancy and the postpartum period: a prospective study. J Sex Marital Ther; 2015, 41(1):49-59.

7. Wright JJ, O'Connor KM. Female sexual dysfunction. Med Clin N Am.; 2015, 99(3):607-28.
8. Elnashar A.M, Ibrahim M., EL-Desoky M.M.,et al. "Female sexual dysfunction in Lower Egypt", BJOG; 2016, 114:201-06.

9. Mansour.S E, Shebl A M, Waheda S M. The Effect of Sexual Counseling Program on Pain Level and Sexual Function among Women with Dyspareunia. J Educ Pract., SSN 22221735 (Paper), 2014, Vol.5, No.3.

10. Khajehei M, Doherty M, Tilley PJ, et al. Prevalence and risk factors of sexual dysfunction in postpartum Australian women. J Sex Med, 2015, 12: 1415-1426.

11. Leeman LM, Rogers RG. Sex after childbirth: postpartum sexual function. Obstet Gynecol2012, 119: 647-655. Johnson CE. Sexual health during pregnancy and the postpartum. J Sex Med 2011, 2011, 8: 12671284.

12. hahraki $Z$, Tanha FD, Ghajarzadeh $M$. Depression, sexual dysfunction and sexual quality of life in women with infertility. BMC Womens Health; 2018, 18(1):92.

13. Banaei M, Tork Zahrani S, PormehrYabandeh A, et al. Investigating the impact of counseling based on PLISSIT model on sexual intimacy and satisfaction of breastfeeding women. Int J Pharm Res Allied Sci; 2016, 5(3):489-99.

14. McCool-Myers M, Theurich M, Zuelke A, et al. Predictors of female sexual dysfunction: a systematic review and qualitative analysis through gender inequality paradigms. BMC Womens Health; 2018, 18(1):108.

15. Kaviani M, Rahnavard T, Azima S, et al. The effect of education on sexual health of women with hypoactive sexual desire disorder: a randomized controlled trial. Int J Community Based Nurs Midwifery; 2014, 2(2):94.

16. Monteiro MN, Medeiros KS, Vidal I, et al. (2019): Non-pharmacological interventions for treating sexual dysfunction in postpartum women: a systematic review protocol. BMJ Open2019;9: e028660. doi:10.1136/bmjopen-2018-028660.

17. Woolhouse $\mathrm{H}$, McDonald E, Brown SJ. Changes to sexual and intimate relationships in the postnatal period: women's experiences with health professionals. Aust J Prim Health, 2014, 20: 298-304.

18. Sayasneh A, Pandeva I. Postpartum Sexual Dysfunction: A literature review of risk factors and role of mode of delivery. BJMP, 2010, 3: 316-320. 
19. Lee JT, Tsai JL, Tsou TS, et al. Effectiveness of a theory-based postpartum sexual health education pro-gram on women's contraceptive use: a randomized con-trolled trial. Contraception, 2011, 84: 48-56.

20. Nezhad MZ, Goodarzi AM. Sexuality, intimacy, and marital satisfaction in Iranian first-time parents. J Sex Marital Ther; 2011, 37:77-88.

21. Shahsiah M, Bahrami F, Etemadi O, et al. Effect of sex education on improving couples marital satisfaction in Isfaha. J Health Syst Res; 2010, 6:690-7.

22. Wallwiener S, Müller M, Doster A, et al. Sexual activity and sexual dysfunction of women in the perinatal period: a longitudinal study. Arch Gynecol Obstet; 2017, 295:873-83.

23. Rosen, R., Brown, C., Heiman, et al. The Female Sexual Function Index (FSFI): A multidimensional self-report instrument for the assessment of female sexual function. J Sex Marital Ther, 2000, 26, 191-208.

24. Diener, E., Emmons, R. A., Larsen, R. J., et al. The Satisfaction with Life Scale. J Pers Assess, 1985, 49, 71-75.

25. El-Gilany, A., El-Wehady, El-Wasify. Updating and validation of the socioeconomic status scale for health research in Egypt. Eastern Mediterranean Health Journal. EMHJ;2012, 18 ( 9 ), 962968.

26. Asselmann E, Hoyer J, Wittchen $\mathrm{H}-\mathrm{U}$, et al. Sexual problems during pregnancy and after delivery among women with and without anxiety and depressive disorders prior to pregnancy: a prospectivelongitudinal study. J Sexual Med; 2016, 13: 95-104.

27. Barbara G, Pifarotti P, Facchin F, et al. Impact of mode of delivery on female postpartum sexual functioning: spontaneous vaginal delivery and operative vaginal delivery vs. cesarean section. J Sex Med; 2016, 13:393-401.
28. Zamani, M., Roudsari. RL, Moradi. M., et al. The effect of sexual health counseling on women's sexual satisfaction in postpartum period: A randomized clinical trial. Int J Reprod Biomed. 2019, 17(1): 4150.

29. Banaei M, Safarzadeh S, Shahrahmani H. Impact of counseling on sexual intimacy of lactating women. Ann Trop Med Public Health [serial online] 2017 [cited 2020 Feb 19];10:1763-9. Available from: http://www.atmph.org/text.asp?2017/10/ 6/1763/222717.

30. Sok C, Sanders JN, Saltzman HM, et al. Sexual behavior, satisfaction, and contraceptive use among postpartum women. J Midwif Women's Health, 2016, 61: 158-165.

31. Elnashar AM, EL-Dien Ibrahim AM, ELDesoky $M M$, et al. Female sexual dysfunction in Lower Egypt. The Authors Journal compilation a RCOG 2007 BJOG An International Journal of Obstetrics and Gynaecology. BJOG; 2007, 114:201-206.

32. Acele EÖ, Karaçam Z. Sexual problems in women during the first postpartum year and related conditions. J Clin Nurs.; 2012, 21 (78):929-37.

33. Karimi A, Dadgar S, Afiat $M$, et al. The effect of sexual health education on sexual satisfaction in couples. Iran J Obstet Gynecol Infertil; 2013, 15:22-30.

34. Hosseini Zand M, Shafiabadi A, Sodani M. The effectiveness of couple therapy based on Islamic teachings on sexual intimacy couples who referred to clinics in Tehran righteous. Soc Psychol; 2012, 25:27-39.

35. Alide SM, Tatiana PK, Jaime B D. Sexual satisfaction in couples in the male and female climacteric stage. Cad. Saúde Pública, Rio de Janeiro;2015,31(2):311320.

36. Schmiedeberg C,Huyer-May B, Castiglioni L, Matthew D Johnson (2016). How Sex Contributes to Life Satisfaction. Archives of Sexual Behavior;2016, 46(2):465-473. 